\title{
Adapting Budgetmaking to Inflation, Icelandic Municipalities in a Volatile Economic Environment
}

\author{
Thorolfur Matthiasson ${ }^{1}$
}

\begin{abstract}
Inflation was a growing problem during the 1960's and the 1970's in Iceland. Inflation represents a problem for any entity that tries to write up a budget, whether an individual, a company or a governmental entity. Many governmental entities do not have right to spend money unless what has been prescribed in the budget. The purpose of this paper is to map out how inflation affected different parts of municipality budgets in Iceland during the 1960's and the 1970's. Furthermore, to look at how well budget makers in the Icelandic municipality sector managed the task of forecasting inflation during the high inflation period of the 1970s.
\end{abstract}

JEL: E31, E37, H68.

Key concepts: Municipalities budgeting, Inflation budgeting, Expectation formation.

1 Thorolfur Matthiasson is a Professor in the Faculty of Economics at the University of Iceland. E-mail: totimatt@hi.is. Data was collected and prepared by Ólafur Hjálmarsson and published in Matthiasson (1987). The data collection was made possible by a grant from the Nordic Economic Council during the period 1982-1985. The Icelandic part of the project was the responsibility of Guðmundur Magnússon, Magnús Pétursson and Thorolfur Matthiasson. The Paper was presented at the symposium in honour of Professor Gudmundur Magnusson, University of Iceland, Reykjavik, November 2007. 


\section{Introduction}

Budgetmaking in public institutions is never an easy task. Policy is changed as new political actors or new political majorities happen to enter the scene. The entrance of new actors or new majorities will almost always result in projects or actions that have budgetary consequences; one politician may have promised to build a bridge, another a school or a kindergarten, a third may have promised to increase the salary of a given group of municipality employees and so on and so forth. To complicate matters further for the budget maker: She has to base her estimates regarding costs of operating the institution on information gathered from bureaucrats that do not necessarily have incentives to share their knowledge in a completely truthful way. To take an example: A bureaucrat in the office of education may choose to send only a low estimate for the cost of a new school if she believes that the probability of a goahead for that building will be increased by doing so. There are incentive mechanisms that can be tailored to induce bureaucrats to reveal correct information but at a cost (see Hindriks and Myles, 2006, chapter 4). Inflation complicates the task of information gathering and information processing in a way that is considerably different from the problems caused by the bureaucrat that supplies information selectively. Note that we have that inflation usually does not affect labour costs in the same manner as it does the price of asphalt or the price of electricity for streetlights. Inflation will also affect the income side of a public budget disparately compared to the cost side. Distinct parts of the costs will be affected in disparate ways, complicating the task of the budget maker still further. The implication is that no matter how good the inflation forecasts are that the budget maker makes there will be some discrepancies, sometimes of considerable magnitude. Prices of some categories of costs may develop differently from other categories. Hence, in times of high inflation the budget maker will have little difficulty in finding excuses for overspending. That opens an avenue for problems of agency at the level of politicians versus voters. Politicians can promise a high level of investment activity, low taxes and budgetary surplus. An outcome with high investment activity and a deficit rather than surplus could be blamed on the uncontrollable and unpredictable effects of inflation. A "smart" budget-making politician may find it opportune to forecast inflation in such a way that the budget gives room for unrealistically high investment level using inflation ex-post as a scapegoat vis-à-vis the electorate.

The purpose of this paper is to map out how inflation affected different parts of municipality budgets in Iceland during the 1960's and the 1970's. Furthermore, to look at how well budget makers in the Icelandic municipality sector managed the task of forecasting inflation during the high inflation period of the 1970s. The organization of the paper is such that an overview of the economic situation in Iceland in the 1960's and the 1970's is given in section 2. Section 3 discusses our calculation of budgeted inflation according to the budget documents of the municipality of Reykjavik. Section 4 reports attempts to convey if the municipality budgetmakers make their inflation forecasts based on the idea of rational expectation or adaptive expectations. Section 5 concludes. 


\section{The Economic Situation in Iceland during the 1960's and the 1970's}

The 1960's and the 1970's were a period of rapid and fundamental changes in the Icelandic economy. The regulation of economic activity introduced during the crisis of the 1930's and the war of the 1940's was still in effect towards the end of the 1950's and the beginning of the 1960 's. In the early 60's external trade was liberalized to some extent and a system of multiple exchange rates was simplified (but not abolished fully). The economy responded positively and growth rates of up to $5 \%$ per capita per annum were registered. The process of rapid growth was abruptly brought to a halt in 1968 with the disappearance of Atlanto-Scandic herring from the fishing grounds around Iceland. Atlanto-Scandic Herring had been the single biggest fish stock in the North-Atlantic and had been fished during its summertime breeding migration in the waters around Iceland by fishers from Iceland, Norway, and the Soviet Union, to name the most active. The intensity of the fishing increased dramatically during the 1960's as equipment improved and number of boats participating in the fishery expanded.

The Icelandic economy recovered quickly, helped by exceptional increases in cod catches that filled the vacuum left by the vanished herring. Economic growth was also inflated by demand pressure created by the reconstruction boom following the Heimaey eruption and investment in equipment to harness geothermal energy as replacement for oil in home heating in the wake of the first oil crises in 1972-3.

The boom of the early 1970's soon proved to be a bit too much of a good thing for the small Icelandic economy. Prices that formerly had increased faster than elsewhere, started to accelerate. Inflation was not only fuelled by demand pressures but also by institutions like wage indexation on the supply side. The praxis of wage indexation had been introduced as early as 1941 (see Jóhannes Nordal, 1996, p. 176). With increasing inflation the wage indexation rules became more and more rigid. Wage indexation and demand-pull proved a dangerous composition where demand driven price increases fed into wage costs inducing "cost-push" price increases. Rigid wage indexation ensured a second round of wage increases and cost induced price increases. Thus, one of the jokes among Icelanders at the time was that frost during early fall in Brazil would increase wages, the reason being that the Brazilian frosty nights would reduce the supply of coffee on the world market, which in turn would induce higher prices of coffee. The coffee price would eventually feed into the price index used to index wages in Iceland! As a consequence of these feedback links, inflation in Iceland took an accelerating path during the 1970's and the 1980's. This can be seen in Figure 1, which shows the percentage increase in the Consumer Price Index (CPI) as well as the percentage increase in the price index for public expenditure (PEI). The theme of this paper is to discuss how well bureaucrats managed to forecast the development of the latter index. The construction of the two indexes is different; the CPI is a traditional Laspeyres price index while the PEI is a Paasche index. Furthermore, the CPI reflects development of prices of consumer goods; both imported and domestically produced, while the PEI reflects the development of costs of producing governmental services. Hence, the wage development of governmental employees weighs heavily in that index. Indexation 
of wages was based on the CPI index, with a lag of 1-3 months. Compensation for increases in the consumer price index was $100 \%$ for long periods.

Figure 1. Development of the general price inflation and inflation in cost of governmental expenditure 1960 to 1982.

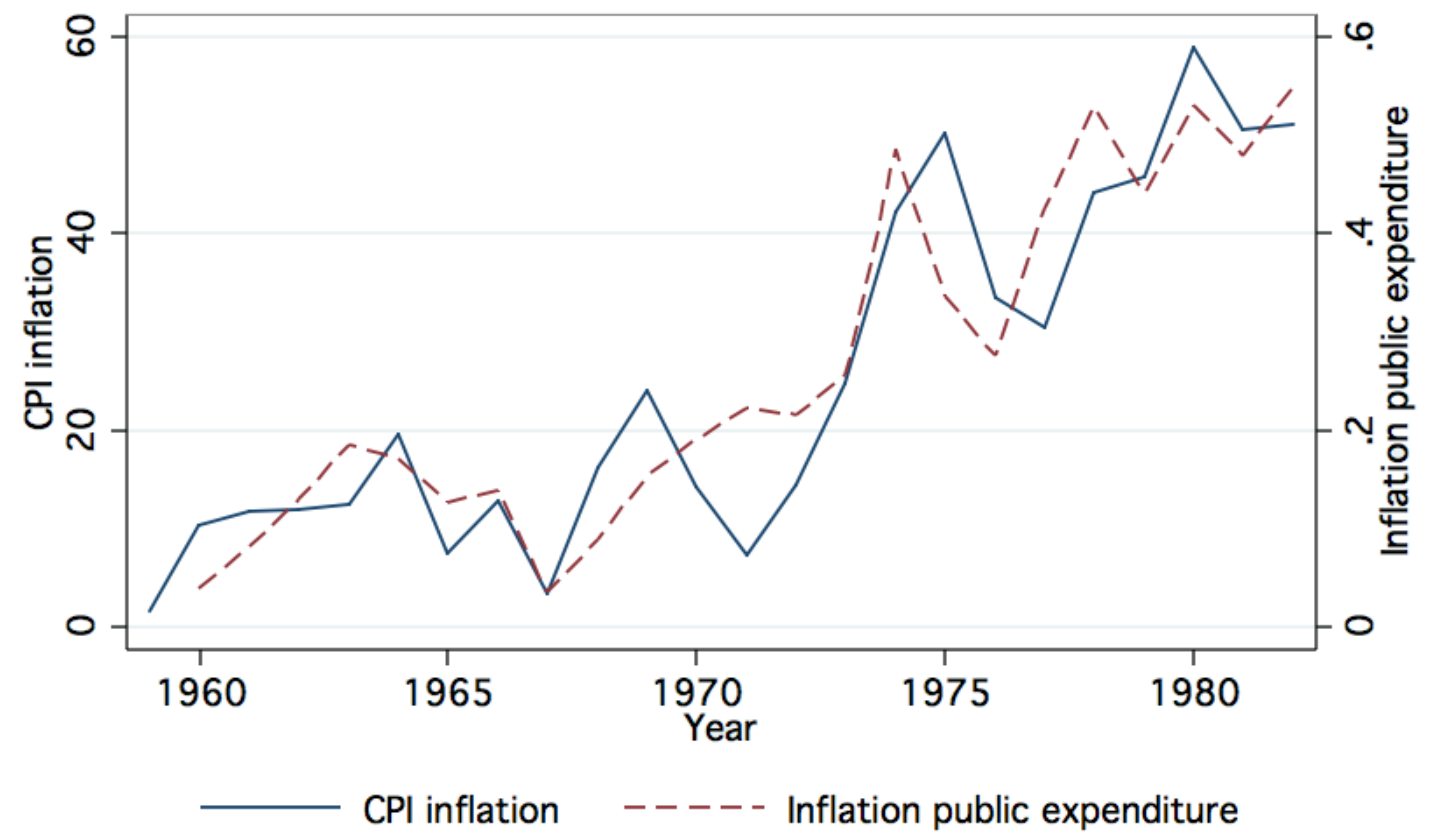

Source: Icelandic historical statistics, Statistics Iceland.

Figure 1 shows that inflation in Iceland was highly volatile during the period even when yearly averages are compared. Public Expenditure inflation seems to lead the CPI inflation some of the years. That seems logical given the feedback mechanism described above: The PEI index reflects wages. A general increase in wages will affect prices with a lag of a few months, starting the process of staggered increases in wages and prices due to indexation. It is not to be expected that the CPI exactly replicate the movement of the PEI as price increase impulses could originate from other sources than that of general wage agreements. Frost in Brazil causing higher coffee prices would be an example of a price impulse that would affect the CPI ahead of the PEI.

\section{Budgeted Inflation according to the Municipality of Reykjavik}

\subsection{Making of a Budget}

Making a budget for a governmental entity is never an easy task. Politicians are subjected to pressures from special interest groups as well as from the public at large when deciding the size of the budget and its distribution between tasks and projects. Budget officials are subjected to pressure from fellow bureaucrats eager to have the funding they believe they need in order to do their assigned job properly. A multitude of interests is involved, partly parallel and partly conflicting. Adding inflation to this mix of interests does increase the degree of complication considerably. 
Also adding to the degree of complication was the fact that exposure to inflation was different for different levels of government. Increase in inflation would increase state income and state expenditure, cet. par. as the state income was to a high degree based on indirect taxes (sales tax, import duties). Hence, both expenditure and income would be moved in the same direction when inflation took unexpected turns. The situation at the municipality level was a bit different before the Pay-As-You-Earn system was introduced in 1988. Municipality income was based on last year's income by individuals and firms and by the valuation of fixed assets (homes/real estate) owned by individuals by December 1st the year prior to payment of the tax. Municipalities thus had their income fixed in nominal terms at the start of the budget year. Changes in inflation would thus hardly have any effect on the nominal income accruing to the municipalities while having the potential of affecting the expenditure part seriously.

Inflation was taken into account in various ways in the state budget during the period under consideration. Towards the end of the period we are investigating it became almost a rule that the Minister of Finance fixed and disclosed a "multiplication factor" for the state budget. This was the factor used to extrapolate from the average price level of the year prior to the budget year into the average price level of the budget year. Hence, if the multiplication factor was $30 \%$, while the average CPI for the year 19X0 was 100, then the budget would be presented on the assumption that the average CPI for year 19X1 would be 130. Ministers of Finance were eager to explain that the multiplication factor was not a projection for the inflation one year ahead as they were not willing to risk political capital on such a risky gamble. The multiplication factor was usually considerably lower than inflation at the time and also considerably lower than inflation expectations of economic agents at the time. The announcement of multiplication factor that was obviously so far out of line with expectations can be interpreted as a vain attempt to nudge inflationary expectations downwards.

The Municipalities were advised by the National Economic Institute on matters relating to general economic prospects, including inflation, when preparing their budgets Snævarr, (2008). As an autonomous governmental institution the National Economic Institute prepared the National Budget based on present knowledge and governmental policy. The National Budget is a political document explicitly based on governmental policy and prospects for parameters exogenous to the Icelandic economy. It could prove a hard task to project the development of the economy when the government proposed unrealistic changes of policy.

The balance of the budget, size of the investment budget and increase in service charges were all matters of debate when municipalities represented their budgets. However, basic parameters such as expected inflation were not discussed at any length.

\subsection{Calculating Unexpected Inflation}

Presumably the municipalities projected the development of nominal costs based on known and expected wage increases and expected inflation as reported by the National Economic Institute. Expected wage increases would presumably weight in 
heavily as municipality services are labour intensive. We decided to back-calculate assumptions by using development of given posts in the budget and the accounts of the City of Reykjavik. We excluded investment and repair from our investigation and used the following formula to calculate unexpected inflation:

$$
\dot{P}_{t+1}^{u}=\frac{A_{t+1}-B_{t+1}}{A_{t}} \cdot \frac{A_{t} / P_{t}}{A_{t+1} / P_{t+1}}
$$

Here, $\dot{P}_{t+1}^{u}$ is increase in price level for municipality inputs (inflation) in year $t+1$ in excess of what was expected at time t. $A_{t+1}$ and $B_{t+1}$ are accrued costs and budgeted costs as recorded in the accounts and the budget, respectively, for year $t+1$. $P_{t}$ stands for price-level in year $t$. The formula is based on the assumption that realized real-increase in accrued costs, $\left(\frac{A_{t}}{P_{t}} / \frac{A_{t+1}}{P_{t+1}}\right)$, of the chosen budget posts was planned. Assume that the real costs do not change from year $t$ to year $t+1$ so that $\left(\frac{A_{t}}{P_{t}} / \frac{A_{t+1}}{P_{t+1}}\right)=1$. Assume further that budgeted costs were assumed to increase by $p \%$. Then $B_{t+1}=(1+p / 100) A_{t}$. Assume also that the accrued costs increase by $n \%$ from year to year so that $A_{t+1}=(1+n / 100) A_{t}$. Plugging these assumptions into equation (1) yields an estimate for unexpected inflation as $(p-n) \%$. Unexpected inflation would be estimated to be zero if $p=n$. Data for the years 1959 to 1972 were collected and used to estimate unexpected inflation for the years 1960 to 1972. Figure 2 shows the development of budgeted versus realized (accrued) expenditure for the chosen budget items according to the budget and the annual profit and loss statements for City of Reykjavik. 
Figure 2. Budgeted versus realized expenditure of selected noninvestment items in constant prices.

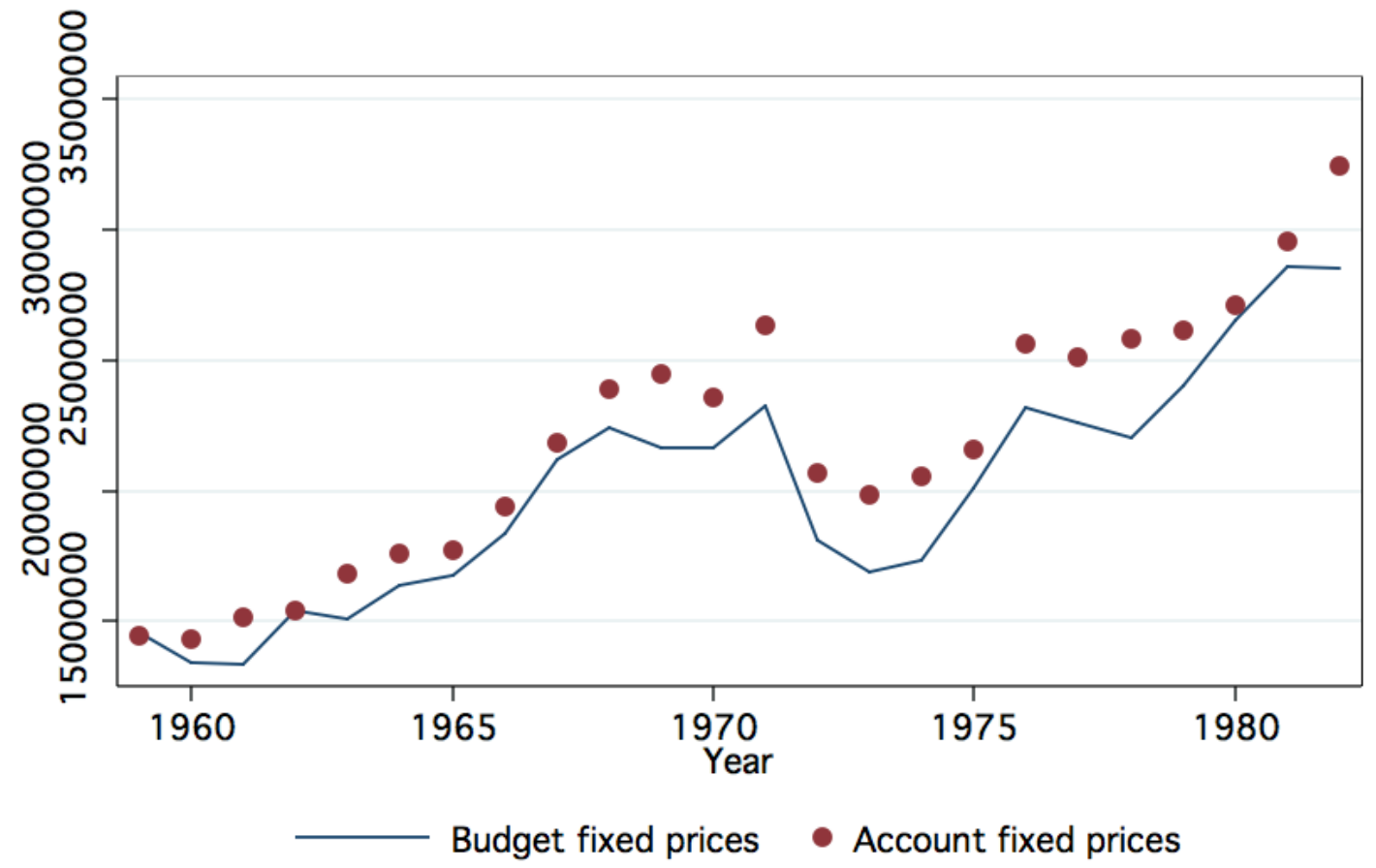

Source: Ársreikningar Reykjavíkur, Statistics Iceland.

The reduction in budgeted and real expenditure in 1972 is due to transfer of funding for law enforcement (policing) from the City of Reykjavik, as well as from other municipalities, to the central government (see Matthiasson, 1983).

\subsection{Calculating Expected Inflation}

Once unexpected inflation has been estimated the calculation of expected inflation is straightforward:

$$
\dot{P}_{t+1}^{e}=\frac{P_{t+1}-P_{t}}{P_{t}}-\dot{P}_{t+1}^{u}=\dot{P}_{t+1}-\dot{P}_{t+1}^{u}
$$

Here $\dot{P}_{t+1}$ stands for realized inflation while $\dot{P}_{t+1}^{e}$ stands for expected inflation. Figure 3 shows the development of expected inflation as well as the development of realized inflation. 
Figure 3. Expected (budgeted) inflation and realized inflation estimated from City of Reykjavik budget papers.

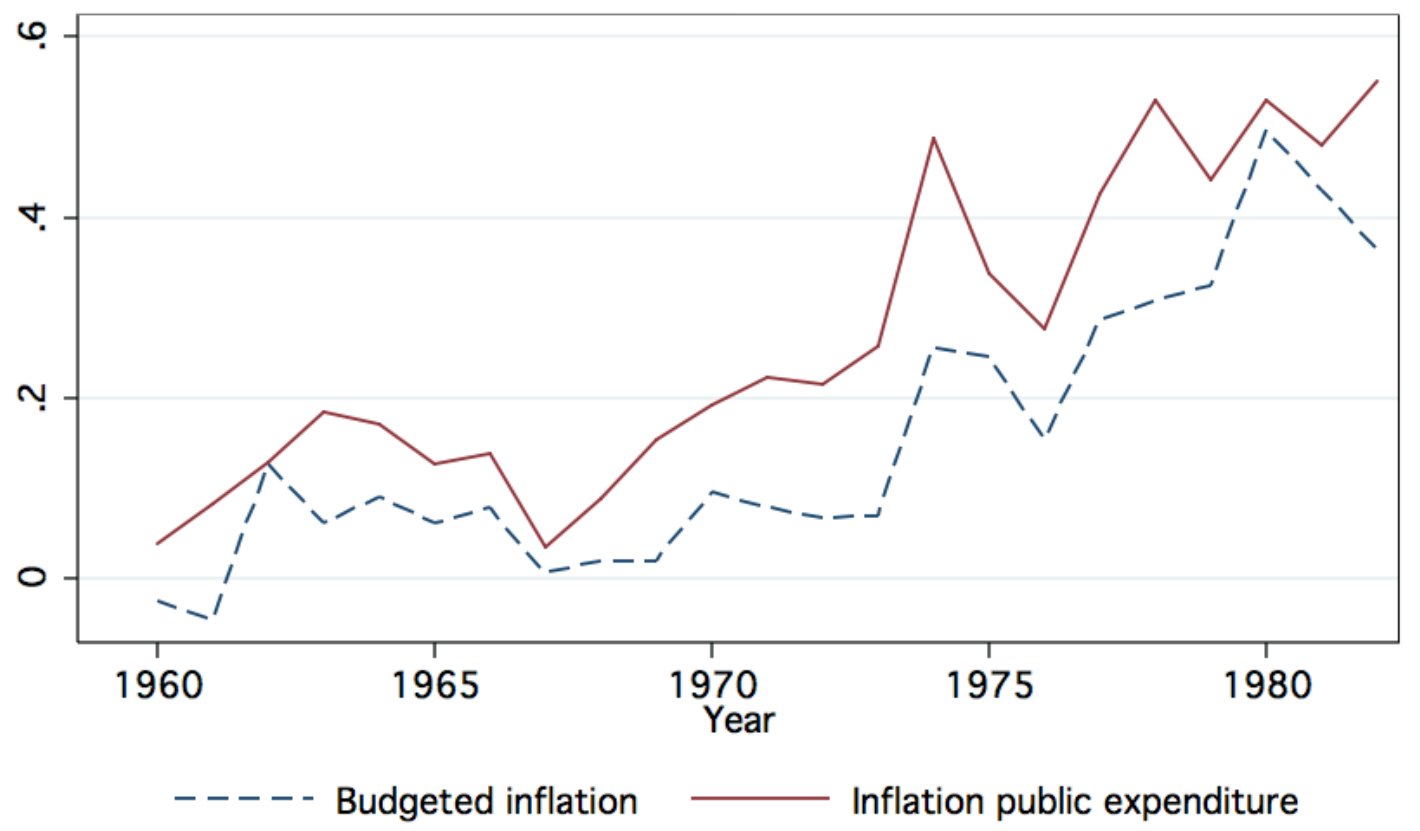

Source: Statistics Iceland and Árbækur Reykjavíkur.

Figure 3 shows that the realized inflation is always higher than the expected inflation as we have estimated it. The figure indicates that expected (budgeted) inflation is systematically lower than realized inflation. The figure also indicates that the budget makers adjusted their expectations to reflect increased or decreased inflationary pressure in the economy.

\section{Brands of Expectation Errors}

Inflation-forecasting errors can have a multitude of origins. In governmental instructions errors can be caused by formal or informal rules and principles. An example is the rule long adopted by the Icelandic Ministry of Finance not to include assumed effects of unfinished wage negotiations in the inflation forecast used in the yearly governmental budget proposal. Such rules make the task of the budget maker easier but the forecast is subject to a systematic downward bias. Yet it is hard to see how to include an assumption about the size of next year's wage increase in the budget proposal, as the budget maker will usually be on the employer's side in wage negotiations. In that case the employees would take any announcement of assumed results from unfinished wage negotiations as a starting point for their demands! Thus no matter how realistically the budget maker forecasts the price and wage level his or her adversaries at the negotiation table will render such efforts inaccurate! Similar arguments can be made for other types of costs where prices are matter of negotiation. A governmental decision maker is at a disadvantage if making perfectly honest forecasts in budget documents prior to finishing important deals.

Inflation-forecasting errors can also be made due to "mechanism" failure. I.e. the budget maker may be using bad models or bad or wrong assumptions to make his/her forecasts. 
Inflation-forecasting errors can also be intentional. Keep the setting for the municipalities in the 1960's and the 1970's in mind. Income was fixed in nominal terms a year ahead. A high estimate for inflation would inflate costs and leave a smaller amount available for investment than would a low estimate of inflation. Many politicians in local politics will agree that running the municipality is the dull part of the job. Working on investment projects and seeing a new project take shape is the fun part. Hence, the bias is to have as much money for investment as possible, taking all the usual side-conditions into consideration (re-electability etc.).

\subsection{Rational Expectations}

In reality errors will be caused by all the effects mentioned above. Models are never perfect, people nudge forecasts into a direction that is "good" for them and all bureaucrats have to follow some set of rules that are inflexible in some significant way. Thus, inflation forecasting is not an exact science. Economists have tried out two partially competing theories regarding the essence of the error. One line of theory suggests that economic agents do not err systematically, i.e. that their expectations are "rational". According to this line of argument we can write realized inflation as function of predicted inflation in the following way:

$$
P_{t}=P_{t}^{e}+\varepsilon_{t}
$$

Here, $\varepsilon_{t}$ is the error made by the forecaster. According to the theory we have that: $E \varepsilon_{t}=0 ; \operatorname{Var}\left(\varepsilon_{t}\right)=\operatorname{Var}\left(\varepsilon_{t+1}\right) ; \operatorname{Covar}\left(\varepsilon_{t}, \varepsilon_{t-j}\right)=0 \forall j \neq 0$.

Keane and Runkle, (1990) propose a test to see if expectations regarding the rate of inflation a period ahead have been formed according to the theory of rational expectation by estimating the parameters of the following equation:

$$
P_{t}=a+b P_{t}^{e}+c Y_{t-1}+e
$$

Here $Y_{t-1}$ is a vector of variables that might be of relevance and known to the forecaster at the time of forecasting. If the theory of rational expectations does hold we have that $E a=0, E b=1$ and $E c=0$. Variables that might be suggested as elements in the $Y$ vector include various data on perceived macroeconomic balance (excess demand, external balance, prospects for the fisheries). Such information was known at a much lower level of precision during the 1960's and 1970's than now. Furthermore, little quantified information from the period is obtainable now. We are thus left with estimating parameters in a simplified version of equation (4). Running the appropriate regression yields:

$$
P_{t}=\underset{(0.0186)}{0.102}+\underset{(0.0865)}{1.049 P_{t}^{e}}
$$

Figures in parentheses are standard deviation of the estimates. We can reject a joint hypothesis that $a=0$ and $b=1$ at $1 \%$ level of significance $\left(F_{2,21}=36.46\right)$. The evidence suggests that budget makers consistently predict inflation at a level $10 \%$ below the realized level. ${ }^{2}$

2 The formulation of the model does not fare well in a Ramsey RESET test, indicating omitted variables. The formulation fares better in Breusch-Godfrey LM test for 


\subsection{Adaptive Expectations}

The rational expectation hypothesis does not seem to fare well when confronted by how the budget makers in the Icelandic municipalities did make their forecasts. An alternative method to model expectations is to assume that the budget maker observes past error and adjusts new forecasts by accepting part of the error as a "mistake" that should be accounted for in the next forecast:

$$
P_{t}^{e}=P_{t-1}^{e}+d\left(P_{t-1}-P_{t-1}^{e}\right)
$$

Here it is assumed that $0 \leq d \leq 1$. If $d=0$ then the budget maker does keep his forecast fixed, irrespective of the error experienced in the past. If $d=1$ the opposite is true and the budget maker uses last period's experience as his forecast for the present period.

A forecaster that sticks to a rule like the one revealed in equation (6) will make predictable errors. Agents making predictable errors are likely to lose money, as other agents will be able to use the knowledge of the errors to come to their own advantage. A bank that systematically under-predicted inflation would underestimate the cost of deposits and charge too low interest on non-indexed loans. Such a bank would soon go out of business in an environment of non-indexed assets. So economic agents can hardly survive in a competitive environment if making forecasts in the fashion of adaptive expectations for variables of importance.

There is no doubt that next year's inflation was a variable of significance for municipalities in the 1960's and the 1970's. But the municipalities did not operate in a competitive environment. And they were not making leveraged bets based on their forecasts regarding the level of inflation as many other players in the economy might have done. ${ }^{3}$ Individuals could only take out loans from the municipalities by being slow in paying their taxes. Hence, while making forecasting errors was potentially bad, it was not to the same degree as in the private sector.

Note also that decisions in a municipality are not made by a monolithic dictator. Bureaucrats prepare information that should help politicians to decide. The politicians have to consider whether they are told the whole truth by the bureaucrats. Furthermore, the politicians may favour biased forecasts for political reasons as already hinted at. Note that the lower the inflation forecast the less of the nominal income already fixed will be needed for the day-to-day operation of the municipality and more can be channelled to investment. A politician in favour of investment in municipality infrastructure (roads, schools, other public buildings, libraries, kindergartens etc.) will also be in favour of not overstating the rate of expected

autocorrelation, where the null hypothesis of no-serial correlation is not rejected (Prob=0.4575).

3 A financial institution does make long term commitments on the asset site but must usually rely on short term deposits for financing these commitments. Such an institution conspicuously underestimating the going rate of interest on deposits some periods into the future will have a long line of customers willing to take loans. If the lenders wait a bit they can redeposit the money in the bank at a profit! Needless to say, there is no limit to the demand that would be created in this way. 
inflation! Politicians with distaste for investment projects might favour a high estimate for expected inflation. Assume that investment-loving municipality politicians outnumber investment-averse politicians. Will it not ruin their reputation as politicians to constantly underestimate the rate of inflation? Well, they can always blame the bureaucrats!

The case for survival of economic agents forming expectations about inflation according to the rule of adaptive expectations is much stronger in the case of the public sector than in the case of the private sector. So let's put the data to test and start out by using the adaptive expectation rule:

$$
P_{t}^{e}=\underset{(0.079)}{0.88^{* * *}} P_{t-1}^{e}+\underset{(0.132)}{0.38^{* * *}}\left(P_{t-1}-P_{t-1}^{e}\right)
$$

The Prais-Winsten routine of STATA is used to estimate the coefficients ( $r h o=-0.31$, adjusted $R^{2}=.94$ ). The three stars indicate significance at the $1 \%$ level. The figures below the estimated parameters are standard deviations. The regression was also run with a constant, which was not significantly different from zero at the $5 \%$ level.

Assume that equation (7) is a correct description of the process used by budget makers to produce inflation forecasts. Then the budget makers will underestimate inflation when prices are accelerating and overestimate inflation when prices are decelerating. But our discussion so far suggests that politicians might react differently when the economy is overheated as compared to when the economic temperature is more normal. This is not easily tested given the data available. One attempt is reported as equation (8):

$$
P_{t}^{e}=\underset{(0.068)}{0.91^{* * *}} P_{t-1}^{e}+\underset{(0.17)}{0.01}\left(P_{t-1}-P_{t-1}^{e}\right)+\underset{(0.21)}{0.62^{* * *}}\left(P_{t-1}-P_{t-1}^{e}\right)\left[\left(P_{t}-P_{t-1}\right)>0\right]
$$

The Prais-Winsten routine of STATA is used to estimate the coefficients (rho $=-0.31$, adjusted $R^{2}=.95$ ). The indication is that budget makers in the municipalities behave differently when predicting inflation in times of accelerating inflation as compared to when inflation is falling. When the economy is overheated, in the sense that inflation is accelerating, then budget makers in the municipalities had tendency to adjust their inflation estimate. When inflation was going down they were more prone to stick to last year's inflation estimate. Note that this behaviour is likely to add to pressure in the economy at inflationary times (by increasing the probability of deficit due to underestimation of inflation) and to reduce pressure in times of contraction (by increasing probability of a surplus as inflation may be overestimated).

\section{Concluding Remarks}

Economists have long assumed that economic agents form expectations in a rational manner, as not doing so would be harmful to their financial health. Some have wondered how frequently economic agents should bother to revise their expectations Haltiwanger, (1985) and Akerlof, (1985). The consensus from this literature seems to be that if some (even small) proportion of the public does revise their priceexpectations infrequently it will have macro-economic consequences. 
Agents in the public sector, whether in central government or in the municipality sector may not have the opportunity to revise their spending plans as frequently as private actors. In addition they may have politically motivated incentives to underestimate inflation rather than overestimate it.

Our results indicate that municipality budget makers are not likely to adjust their projection for next period's inflation in big steps. Our results also indicate that their behaviour is different when there is pressure in the economy as opposed to when there is less pressure.

The asymmetry is likely to induce policy makers to underestimate inflation at time of pressure and overestimate inflation at time of less pressure. The consequence of underestimation of inflation is likely to be that "too much" funds are channelled to municipality investment. At the end of the day the municipalities are likely to overspend. The tendency to underestimate inflation would thus have contributed to further increasing the instability of the Icelandic economy in the time under consideration.

\section{References}

Akerlof, G. A., \& Yellen, J. L. (1985). Can Small Deviations from Rationality Make Significant Differences to Economic Equilibria? American Economic Review, 75(4), 708720.

Haltiwanger, J., \& Waldman, M. (1985). Rational Expectations and the Limits of Rationality: An Analysis of Heterogeneity. American Economic Review, 75(3), 326-340.

Hindriks, J., \& Myles, G. D. (2006). Intermediate Public Economics. Cambridge, Mass: MIT Press.

Nordal, J., \& Kristinsson, V. (Eds.) (1996). Iceland, the Republic. Reykjavik: Central Bank of Iceland.

Keane, M. P., \& Runkle, D. E. (1990). Testing the Rationality of Price Forecasts - New Evidence from Panel Data. American Economic Review, 80(4), 714-735.

Matthiasson, T., (1983). Islandske erfaringer. In: Lars Anderson (Ed.), Kommunenes rolle i stabiliseringspolitikken (pp. 101-158). Oslo: Nordisk Ökonomisk Forskningsråd/ Universitetsforlaget.

Matthiasson, T., (1987). Inflasjon og opplåning, hoorfor opptar islandske kommuner lån? Reykjavik: Bureau of the Budgtet, Ministry of Finance.

Snævarr, S. (2008). Personal Communication. Reykjavik. 